\title{
MAPEAMENTO DE SUSCETIBILIDADE À INUNDAÇÃO UTILIZANDO O MÉTODO DA RAZÃO DE FREQUÊNCIA APLICADO À BACIA DO RIACHO FUNDO - DISTRITO FEDERAL
}

\author{
FLOOD SUSCEPTIBILITY MAPPING USING THE FREQUENCY RATIO METHOD APPLIED TO \\ THE RIACHO FUNDO BASIN - FEDERAL DISTRICT
}

Hugo Leonardo Oliveira Chaves, Maria Elisa Leite Costa, Sérgio Koide, Tati de Almeida, Rejane Ennes Cicerelli

Universidade de Brasília

eng.hugochaves@gmail.com, mariaelisaleitecosta@hotmail.com, skoide@unb.br, tati almeida@unb.br, rejaneig@unb.br

Submissão: 11 de dezembro de 2020 Aceitação: 23 de março de 2021

\section{Resumo}

O mapeamento de suscetibilidade à inundação é importante para o manejo da dinâmica do uso do solo e, consequentemente, da hidrologia urbana local. O presente estudo produziu o mapa de suscetibilidade à inundação na Bacia do Riacho Fundo, Distrito Federal, utilizando o método estatístico bivariado Razão de Frequência (Frequency Ratio), com 30 pontos de inundação observados em 2018 como pontos de treinamento $(71 \%)$ e outros 12 pontos de inundação (29\%) como pontos de validação para desenvolvimento do modelo. O modelo é composto de 12 fatores de influência: declividade, curvatura, aspecto, hipsometria, distância dos rios, índice de potência de escoamento, índice de transporte de sedimento, índice topográfico de umidade, índice de rugosidade do terreno, índice de escoamento superficial, uso e cobertura do solo e geologia. Todas as variáveis com um tamanho de pixel de $12,5 \mathrm{~m} \times 12,5 \mathrm{~m}$. Os fatores de uso e cobertura do solo e geologia local mostraram-se os mais influentes no modelo. A validação do modelo foi realizada utilizando o método da área sob a curva, com uma acurácia de $85,75 \%$. O estudo mostra que o método pode ser usado para auxiliar no estudo de planos de controle e mitigação de inundação em centros urbanos, como a locação preliminar de bacias de detenção.

Palavras-chave: suscetibilidade, inundação, mapeamento, razão de frequência, geoprocessamento.

\section{Abstract}

Flood susceptibility mapping is important to the management of the urban hydrological dynamic and to the studies conducted to prevent the flood-based problems. This study has produced a flood susceptibility map using a bivariate statistical analysis named frequency ratio (FR) model applied in the Riacho Fundo catchment, with 30 flooding locations $(71 \%)$ for statistical analysis as training dataset and 12 remaining points $(29 \%)$ were applied to validate the developed model. Twelve conditioning factors were considered in this study: slope, curvature, aspect, elevation, distance to river, stream power index (SPI), sediment transport index (STI), topographic wetness index (TWI), terrain roughness index (TRI), superficial runoff index, land use/land cover (LULC) and geology. All these variables were resampled into $12.5 \times 12.5 \mathrm{~m}$ pixel size. The model showed LULC and geology as the most influential factors in flooding. The AUC for success rate was $85.75 \%$ with the training points. The study shows the method can be used in studies of plans to mitigate and control flooding in urban centers, as preliminary lease of ponds.

Keywords: susceptibility, flooding, mapping, frequency ratio, geoprocessing.

\section{INTRODUÇÃO}

Inundações e enchentes são ameaças naturais devastadoras que podem causar danos às infraestruturas e à sociedade (SAMANTA et al., 2018). Identificar áreas suscetíveis à inundação é uma tarefa importante para o estudo e prevenção das consequências desse fenômeno (ALI et al., 2020). Segundo Tehrany et al. (2018), inundações são resultado da forte chuva em um 
curto espaço de tempo, em locais onde há impermeabilização de uma grande área, geralmente causada pela urbanização, provocando a cheia de rios e encobrindo regiões adjacentes. Enchentes e inundações são consideradas os tipos de desastres naturais mais comuns e os que geram maiores prejuízos, em termos econômicos e humanos, sendo responsáveis por cerca de $31 \%$ do total de danos à economia provenientes de eventos naturais catastróficos (YALCIN; ARYUREK 2004; DANO et al., 2019). Desta forma, é fundamental erradicar ou minimizar os possíveis danos causados pelas inundações, e uma ferramenta inicial é o mapeamento das áreas suscetíveis, pois com ele é possível planejar a locação de estruturas de engenharia.

Os modelos mais utilizados para modelagem de suscetibilidade à inundação são os seguintes: método da Razão Frequência (FR), Rede Artificial Neural (ANN), Processo Hierárquico Analítico (AHP), Lógica Fuzzy, Lógica de Regressão e Peso de Evidência (WoE) (SAMANTA et al., 2018). O Processo Hierárquico Analítico e a Lógica Fuzzy são as principais técnicas qualitativas mais comumente usadas em avaliação de suscetibilidade à inundação (RAHMATI et al., 2016), enquanto métodos como a Razão de Frequência (FR), o Peso da Evidência (WoE) e a Regressão Logística (LR) são mais utilizados como métodos quantitativos (BUl et al., 2019).

O método da Razão de Frequência consiste em uma análise estatística bivariada (BSA) de cada classe de fatores que influenciam no fenômeno da inundação em relação às suas áreas de ocorrência (TEHRANY et al., 2015). Tal método foi proposto por Tehrany et al. (2014) para áreas com alto índice de urbanização e declividade moderada, condições semelhantes às da região deste estudo, qual seja, a Região Administrativa de Vicente Pires, localizada na Bacia do Riacho Fundo.

Nesse sentido, este trabalho tem como objetivo o mapeamento das áreas suscetíveis à inundação na Bacia do Riacho Fundo (Distrito Federal), a fim de apoiar políticas públicas de mitigação, tais como construções de bacias de detenção.

\section{MATERIAL E MÉTODOS}

Área de Estudo
A área de estudo escolhida é a unidade hidrográfica do Riacho Fundo, localizada dentro da bacia hidrográfica do Lago Paranoá, Distrito Federal. Essa unidade hidrográfica possui uma área de $217 \mathrm{~km}^{2}$, o que corresponde a aproximadamente $75 \%$ da área da bacia do Lago Paranoá, que tem área de $288,69 \mathrm{~km}^{2}$ (SEMARH, 1999). A unidade hidrográfica do Riacho Fundo (Figura 1) tem como principais cursos d'água os córregos Vicente Pires e Guará, os quais são afluentes do córrego Riacho Fundo, sendo este o responsável pelo abastecimento do Lago Paranoá, corpo hídrico de grande importância social e ecológica na região de Brasília (NETO et al., 2017).

A bacia pode ser dividida em função de seus dois principais córregos, o Riacho Fundo e o Vicente Pires. As áreas adjacentes ao córrego Vicente Pires são mais urbanizadas e as do córrego Riacho Fundo mais rurais, sendo observadas, no entanto, expansões urbanas em suas cabeceiras, representadas por condomínios residenciais de baixa renda (AQUINO et al., 2018).

A Região Administrativa do Vicente Pires no Distrito Federal é marcada por ocorrências de inundações devido à desordenada e rápida urbanização da área (DE PAULA et al., 2017; CEOLIN et al., 2019). Segundo o Governo do Distrito Federal (GDF), até 2019, foram construídas 11 bacias de detenção e o planejamento previu a construção de mais 22 , até o final de 2020 (AGÊNCIA BRASÍLIA, 2019). Essas estruturas de engenharia são utilizadas com o objetivo de captar e descarregar as águas precipitadas e escoadas nos córregos locais com vazões menores, provocando o amortecimento das vazões (HIPÓLITO et al., 2019). As águas afluentes das bacias são descarregadas no Córrego Vicente Pires, por meio de dissipadores de energia, a fim de evitar a erosão do solo e o surgimento de voçorocas.

\section{Dados Espaciais e Programas Utilizados}

Os softwares utilizados para o processamento das informações desta pesquisa foram o ArcGIS $^{\circledR}$ versão $10.6 .1 \mathrm{com}$ a extensão HEC-GEO HMS, para obtenção do escoamento superficial pelo método SCS-Curva Número, e o Hydrology National Engineering Handbook, para a obtenção da tabela de curva número do solo. Os dados vetoriais utilizados e suas respectivas fontes encontram-se listados no Quadro 1. 
Figura 1. Mapa de localização da bacia do Riacho Fundo (Brasília - DF) com os pontos de inundação da Bacia do Riacho Fundo (DF) obtidos e utilizados para modelo (pontos de treinamento) e de validação.

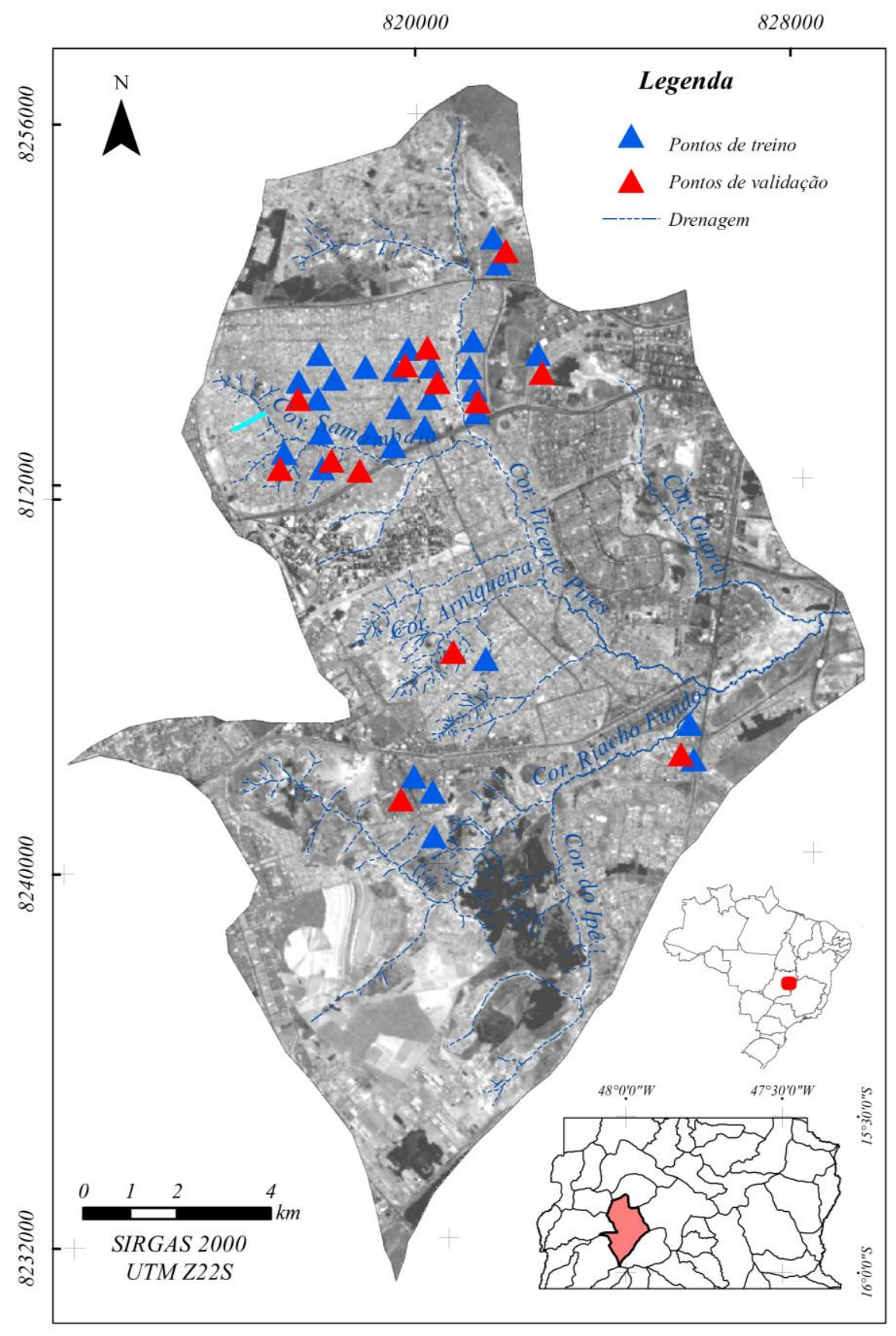

Fonte: Geoportal/ GDF (https://www.geoportal.seduh.df.gov.br/)

Inventário das áreas de inundação

O inventário das áreas de inundação é essencial para o estudo da correlação entre as ocorrências de inundação e os diferentes fatores de influência (KHOSRAVI et al., 2016). Os pontos que representam as áreas com histórico de inundação são divididos em dois grupos: um grupo para o treinamento e desenvolvimento do modelo e outro para o processo de validação. Os dados de treinamento auxiliam na atribuição do peso a cada um dos fatores de influência, enquanto os pontos de validação são utilizados para avaliar a acurácia e precisão do modelo (PRADHAN et al., 2014, CANIANI et al., 2008; TEHRANY et al., 2015b). Todavia, não há instrução que defina como os dados devem ser divididos nesses dois grupos (PRADHAN; LEE, 2010). Neste trabalho, foram definidos, 
aleatoriamente, 30 pontos de treinamento e 12 pontos de validação do modelo (Figura 1). Todos os fatores matriciais foram redimensionados para uma resolução espacial de $12,5 \mathrm{~m}$ e escala de 1:100.000 para dados vetoriais.

\section{Quadro 1: Dados vetoriais utilizados e suas respectivas fontes de consulta}

\begin{tabular}{|l|l|l|}
\hline Dados & Fonte & Endereço \\
\hline $\begin{array}{l}\text { Áreas } \\
\text { históricos com } \\
\text { inundação }\end{array}$ & Geoportal GDF & https://www.geoportal.seduh.df.gov.br/ \\
\hline Mapa de solos & $\begin{array}{l}\text { Zoneamento } \\
\text { Ecológico- } \\
\text { econômico/GDF }\end{array}$ & http://www.zee.df.gov.br/ \\
\hline Geologia & $\begin{array}{l}\text { Campos et al. } \\
(2013)\end{array}$ & \\
\hline Precipitação mensal & CAESB & https://atlas.caesb.df.gov.br/hidrometeorologia/ \\
\hline $\begin{array}{l}\text { Curvas de nível }- \\
\text { Equidistância de 5 } \\
\text { metros }\end{array}$ & Geoportal GDF & https://www.geoportal.seduh.df.gov.br/ \\
\hline $\begin{array}{l}\text { Hidrografia de } \\
(1: 100000)\end{array}$ & Geoportal GDF & https://www.geoportal.seduh.df.gov.br/ \\
\hline $\begin{array}{l}\text { Uso e cobertura do } \\
\text { solo de 2018 } \\
(1: 100.000)\end{array}$ & Mapbiomas & https://mapbiomas.org/ \\
\hline
\end{tabular}

Fonte: Os Autores.

\section{Fatores de influência}

Os fatores de influência em inundação urbana são diversos e cada um tem uma contribuição particular para o evento (RAHMATI et al., 2015). A modelagem de suscetibilidade à inundação conta com uma seleção apropriada dos fatores de influência na região de estudo para a obtenção de um modelo confiável, pois um fator pode ser muito influente em uma bacia específica, mas não ter a mesma influência em outras áreas (KIA et al., 2012).

Foram selecionados os fatores: declividade, curvatura, aspecto, hipsometria, distância dos rios, índice de potência de escoamento (Stream Power Index - SPI), índice de transporte de sedimento (Sediment Transport Index - STI), índice topográfico de umidade (Topographic Wetness Index -TWI), índice de rugosidade do terreno (Terrain Roughness Index - TRI), índice de escoamento superficial (Q), uso e cobertura do solo e geologia. Esses fatores foram selecionados com base na literatura e são de natureza nominal, ordinal e razão. Todos os fatores foram classificados usando um método quantil, requerido para a análise de Razão Frequência (TEHRANY et al., 2015b). O método permitiu produzir classes de suscetibilidade com o mesmo número de ocorrências. Os índices de probabilidade de inundação foram classificados em cinco zonas de suscetibilidade, a saber, muito baixo, baixo, médio, alto e muito alto. $\mathrm{O}$ fluxograma da Figura 2 apresenta os procedimentos metodológicos adotados na pesquisa. Produtos derivados do Modelo Digital de
Elevação-MDE

O Modelo Digital de Elevação (MDE) usado neste trabalho foi obtido a partir de curvas de nível com equidistância de $5 \mathrm{~m}$, disponibilizado no geoportal do GDF. As curvas de nível foram interpoladas utilizando o método Topo to Raster no ArcGIS, que é especificamente desenhado para a obtenção de MDE's hidrologicamente consistido (ESRI, 2018). A partir do MDE, foram obtidos a declividade, curvatura, aspecto $e$ hipsometria. A declividade é um dos fatores de influência mais importantes no estudo da inundação em uma bacia, pois tem efeito direto no escoamento superficial e infiltração, além de ter um papel decisivo na erosão do solo. A declividade foi classificada em seis classes $(0 \%$ $3 \% ; 3 \%$ - 8\%; 8\% - 20\%; 20\% - 45\%; 45\% - 75\%; $>75 \%)$. 
Figura 2. Fluxograma dos métodos utilizados nesta pesquisa para a confecção do Mapa de Suscetibilidade à inundação

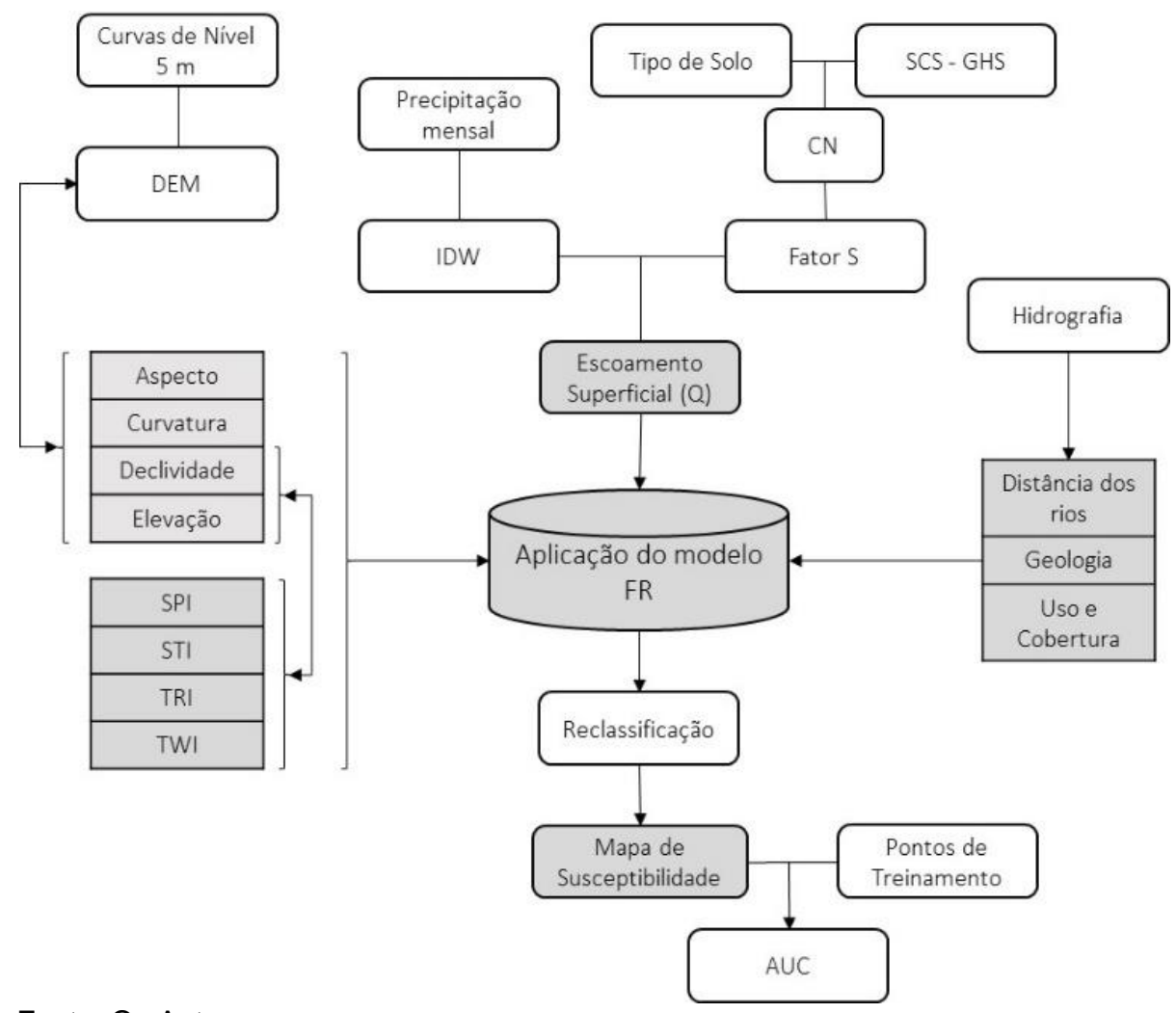

A curvatura do terreno reflete a forma da área analisada (KHOSRAVI et al., 2019). Três classes foram atribuídas à curvatura: a negativa representa a concavidade do terreno, a curvatura positiva representa a convexidade do terreno e a curvatura zero representa a planicidade.

O aspecto é um fator importante para a análise da estabilidade geomorfológica por controlar alguns parâmetros, como a exposição à radiação solar, vento, intensidade de precipitação e umidade do solo (HAGHIZADEH et al., 2017). Uma aplicação de fator aspecto é determinar a direção do fluxo de água (HONG et al. 2017). Esse fator foi dividido em nove classes: flat, north, northeast, east, southeast, south, southwest, west and northwest.

O estudo de altimetria é relevante para a análise das formas do relevo, indicando condições mais propícias aos escoamentos das águas nas áreas de maior altitude e de acumulação hídrica para as áreas de menor altitude (MIRANDA et al., 2019).

Distância dos rios

De acordo com Mojaddadi et al. (2017), ocorrências de inundações são frequentes ao

longo do curso d'água. A distância dos rios foi considerada um fator de influência relacionado à geomorfologia da área. O mapeamento da distância dos rios foi gerado por influenciar o potencial de infiltração de solo (PHAM et al., 2015). A distância dos rios é representada pela proximidade de rios e drenagens na área e é importante, pois o nível dos rios sobe devido às chuvas fortes, podendo causar extravasamento das águas, inundando áreas mais próximas. Quanto mais distante do rio, menor a possibilidade de sofrer com esse fenômeno. Esse produto foi gerado a partir do vetor de hidrologia disponibilizado no geoportal de GDF usando a ferramenta Euclidian Distance no ArcGIS. O fator de distância dos rios é contínuo e varia de zero a $4.343,28$ metros, ou seja, quanto mais próximo dos rios o valor atribuído ao pixel é próximo de zero.

Índice de Potência de Escoamento (Stream Power Index - SPI)

O índice de potência de escoamento (SPI) é baseado na suposição de que o escoamento é relativo a uma superfície topográfica específica, sendo este a medida de potencial de erosão no 
escoamento de água (MOORE et al., 1991). Em resumo, é o índice que mede o poder erosivo devido ao escoamento superficial (KHOSRAVI et al., 2016). O SPI é calculado pela equação 1 .

$$
S P I=\alpha \tan \beta
$$

Em que:

SPI é o índice de potência de escoamento;

$\alpha$ é a área da bacia $\left(\mathrm{m}^{2}\right)$;

$\beta$ é o gradiente de inclinação (em graus).

Índice de Transporte de Sedimento (Sediment Transport Index - STI)

O Índice de Transporte de Sedimento considera a área de contribuição do acréscimo da parte mais alta da declividade, supondo que essa área de contribuição está diretamente relacionada à vazão e à declividade (TEHRANY et al., 2018). É um índice usado para o estudo da erosão e para a convergência e divergência do fluxo de água, tendo efeito na ocorrência de inundações (KHOSRAVI et al., 2019). O STI é definido por Moore et al., (1991) de acordo com a equação 2.

$S T I=\left(\frac{a}{22,13}\right)^{0,6}\left(\frac{\sin \beta}{0,0896}\right)^{1,3}$

Em que:

STI é o índice de transporte de sedimento; $\alpha$ é a área da bacia $\left(\mathrm{m}^{2}\right)$

$\beta$ é o gradiente de inclinação (em graus).

Índice Topográfico de Umidade (Topographic Wetness Index - TWI)

O Índice Topográfico de Umidade (TWI) combina a área de contribuição a montante de uma determinada célula com o declive dessa mesma célula, o que descreve a sua tendência em acumular água (LIMA et al., 2020). A quantidade de fluxo a se acumular em qualquer ponto da área da bacia pode ser calculada pelo TWI e pela tendência da água de descer a encosta usando a força da gravidade (MOORE et al., 1991). O TWI é um índice efetivo para a análise de potencial de inundação (KHOSRAVI et al., 2016). Moore (1991) define TWI conforme a equação 3.

$$
T W I=\ln \left(\frac{\alpha}{\beta}\right)
$$

Em que:
TWI é o índice de topográfico de umidade; $\alpha$ é a área da bacia $\left(\mathrm{m}^{2}\right)$;

$\beta$ é o gradiente de inclinação (em graus).

Índice de Rugosidade do Terreno (Terrain Roughness Index - TRI)

O índice de Rugosidade do Terreno é um índice topográfico morfométrico amplamente usado em modelagem de suscetibilidade à inundação, que expressa a heterogeneidade da superfície da área de estudo (KORZENIOWSKA et al., 2017). Tal índice é utilizado para verificar a rugosidade do terreno diante da variação altimétrica ao redor de um determinado ponto da superfície. Assim, quanto mais uniforme for o relevo em uma determinada área, menor será o índice de rugosidade (RILEY et al., 1999). O índice calcula a diferença nos valores de elevação de uma célula central $\left(x_{00}\right)$ e das oito células vizinhas $\left(x_{i j}\right)$, em seguida, ele eleva ao quadrado a somatória das diferenças de elevação para torná-lo positivo. O índice é então derivado tomando a raiz quadrada desse valor $e$ corresponde à mudança de elevação média entre qualquer ponto em uma grade e sua área circundante.

$T R I=\sqrt{\left(\sum\left(x_{i j}-x_{00}\right)\right)^{2}}$

Em que $x_{00}$ é a célula central e $x_{i j}$ é a média das oito células vizinhas em uma vizinhança de $3 \times 3$ pixels.

Índice de Escoamento Superficial (Q)

$\mathrm{O}$ índice de escoamento superficial foi obtido utilizando o método da Curva Número (CN). Esse método foi elaborado pelo United States Department of Agriculture - Soil Conservation Service (USDA-SCS, 1972) e consiste em identificar características referentes ao potencial de escoamento superficial, baseando-se no conceito de que a lâmina de escoamento é uma função da altura total da lâmina precipitada, que ocorre devido à infiltração da interceptação vegetal e da retenção em depressões do terreno (ARAÚJO NETO et al., 2012; SANTOS; LOLLO, 2016). Esse índice utiliza o parâmetro $C N$, que é um índice adimensional de escoamento determinado com base no Grupo Hidrológico do Solo (GHS), uso e cobertura do solo, e nas Condições Antecedentes de Umidade, e varia do 
muito permeável, de valor atribuído zero, ao impermeável, de valor 100 (MELESSE et al., 2002). Soares et al. (2017) levantam a questão sobre a veracidade dos resultados do método, que atribui pesos numéricos a matrizes resultantes da inter-relação de variáveis importantes, como tipos de solo e uso do solo, e concluem que os resultados desse método podem ser validados com a vazão, refletindo a realidade de maneira satisfatória.

Seguindo a proposta metodológica de Mantovani e Bacani (2018), buscou-se na literatura uma tabela com valores de solos, de acordo com os dados de uso e cobertura, na bacia do Riacho Fundo, usando como base 0
National Engeneering Handbook da Natural Resources Conservation Service (United States Departament of Agriculture) e os valores da tabela de Tucci (1993). Classificou-se o solo de acordo com os critérios gerais propostos para elaboração dos grupos hidrológicos de solo (GHS) pelo atual Sistema Brasileiro de Classificação de Solos (SiBCS) (EMBRAPA, 2018), e o mapa de solos utilizado neste trabalho foi obtido no site de Zoneamento EcológicoEconômico do Distrito Federal (ZEE-DF, 2020). Por fim, o processamento foi efetuado por meio da fusão dos mapas de uso da terra e cobertura do solo e o GHS por meio da extensão HECGeoHMS, como mostra a Tabela 1.

Tabela 1. Estimativa dos valores de $\mathrm{CN}$

\begin{tabular}{l|c|c|c|c|c}
\hline \multicolumn{1}{c|}{$\begin{array}{c}\text { Classificação UeO } \\
\text { MapBiomas }\end{array}$} & Classificação SiBCS & \multicolumn{4}{|c}{ Grupo Hidrológico do Solo } \\
\cline { 3 - 6 } & & A & B & C & D \\
\hline Formação Florestal & Floresta Natural Densa & 25 & 52 & 62 & 69 \\
\hline Formação Savânica & Floresta esparsa & 46 & 68 & 78 & 84 \\
\hline Formação Campestre & $\begin{array}{c}\text { Campos densos, alta } \\
\text { transpiração }\end{array}$ & 25 & 55 & 70 & 77 \\
\hline Floresta Plantada & Silvicultura & 36 & 60 & 70 & 76 \\
\hline Pastagem & Pastagem & 25 & 59 & 75 & 83 \\
\hline Cultura Anual e Perene & Agricultura & 68 & 71 & 78 & 81 \\
\hline Infraestrutura Urbana & Áreas Urbanas & 77 & 85 & 90 & 92 \\
\hline Outra Área Não vegetada & Solo Exposto & 70 & 80 & 87 & 90 \\
\hline Rio, Lago, Oceano & Corpo D'água & 100 & 100 & 100 & 100 \\
\hline Fon & & & & &
\end{tabular}

Fonte: Os Autores.

A segunda etapa do processo consiste em obter a capacidade máxima de armazenamento de água no solo, representada pelo fator $\mathrm{S}(\mathrm{mm})$ presente na equação 5 :

$S=\left(\frac{25.400}{C N}\right)-254$

Para o cálculo de índice de escoamento superficial $(Q)$, obteve-se a média mensal de precipitação para o ano de 2018 de seis pluviógrafos, mantidos pela Agência Nacional de Águas (ANA), da Companhia de Água e Esgoto de Brasília (CAESB) e do PTARH/UnB. Para a geração da superfície, utilizou-se o método de interpolação determinístico da Ponderação pelo Inverso da Distância (IDW), que determina como valores das células uma combinação linear ponderada dos pontos amostrados (ESRI, 2018).

A etapa final consiste em obter o dado matricial de Índice de Escoamento Superficial $(Q$, equação 6).

$$
Q=\frac{(P-0,2 x S)^{2}}{P+0,8 x S}
$$

Em que:

$\mathrm{P}$ corresponde à precipitação média mensal ( $\mathrm{mm} / \mathrm{mês})$;

$S$ é a capacidade máxima de armazenamento de água (saturação em $\mathrm{mm}$ ) da camada superior do solo na bacia hidrográfica.

\section{Uso e Cobertura do Solo}

O entendimento detalhado do uso e cobertura do solo é essencial para a modelagem de vulnerabilidade a desastres naturais. Áreas de vegetação são menos propícias a inundação, enquanto áreas urbanas são tipicamente compostas por superfícies impermeabilizantes e solo compactado, tornando-as mais suscetíveis a inundações (MOJADDADI et al., 2017). Foi utilizado o mapa de uso e cobertura do solo 
disponibilizado pelo MapBiomas para o ano de 2018, em uma escala de 1:100.000 e possui nove classes.

\section{Geologia}

A formação litológica do solo informa sobre a capacidade do solo em absorver água, que está relacionada diretamente à geologia (RAMESH; IQBAL, 2020). Os dados de geologia foram obtidos do trabalho de Campos et al. (2013), e os tipos litológicos encontrados na área são: ardósia, quartzito fino e ritmito.

Razão de Frequência (FR)

O método da Razão de Frequência é uma análise estatística bivariada com o propósito de estabelecer uma correlação quantitativa entre uma variável dependente e outra independente (equação 7). Esse método foi usado para avaliar o impacto da ocorrência de inundações de acordo com cada um dos fatores de influência escolhidos. A FR é a expressão da razão de probabilidade de uma ocorrência com relação a uma não-ocorrência para um atributo qualquer. Quanto maior for o valor FR, mais substancial é a relação entre a ocorrência do fenômeno e uma variável específica (RAHMATHI et al., 2015). O índice suscetibilidade à inundação (FSI) (equação 8) é calculado como a soma das razões frequências (FR) para todos os parâmetros ou fatores (KHOSRAVI et al., 2016).

$$
\begin{aligned}
& F R=\left[N_{p i x}\left(S X_{i}\right) / \sum_{i=1}^{m} S X_{i}\right] /\left[N_{p i x}\left(X_{j}\right) / \sum_{j=1}^{n} N_{p i x}\left(X_{j}\right)\right] \\
& F S I=\sum_{j=1}^{n} F R
\end{aligned}
$$

Em que:

$N_{p i x}\left(S X_{i}\right) \quad$ é o número de pixels de ocorrência de inundação dentro de uma classe $i$ do fator variável $X_{i}$;

$N_{p i x}\left(X_{j}\right)$ é o número de pixels total dentro de um fator variável de uma classe $i$ do fator variável $X_{i}$

$m$ é o número de classes nos parâmetros variáveis $X_{i}$;

$n$ é o número de fatores na área de estudo.

A razão de frequência (FR) mais alta indica uma forte correlação entre os fatores condicionantes e as ocorrências de inundações (TEHRANY et al. 2014). Portanto, os valores maiores ou menores que 1 (um) representam uma relação forte ou fraca, respectivamente (PRADHAN et al., 2014).

$\mathrm{Na}$ tentativa de mostrar a relação entre as áreas inundadas identificadas com $\mathrm{o}$ valore de FR, também foi realizada uma análise de correlação entre as classes dos fatores condicionantes com o valor de FR. O modelo mostra a probabilidade de FR para cada fator de condicionante.

\section{Validação}

A validação foi feita utilizando o método chamado Área Sob a Curva (Area Under Curve $A \cup C)$ com pontos de validação nos locais de inundação (Figura 1). O método é utilizado para uma avaliação quantitativa de acurácia de predição.

\section{RESULTADOS E DISCUSSÃO}

\section{Distribuição dos fatores condicionantes}

Os parâmetros independentes assinalados declividade (Figura 3A), curvatura (Figura 3B), hipsometria (Figura $3 C$ ), índice de potência de escoamento (Stream Power Index - SPI) (Figura 3D), índice de rugosidade do terreno (Terrain Roughness Index - TRI) (Figura 3E), índice de transporte de sedimento (Sediment Transport Index - STI) (Figura 3F), índice topográfico de umidade (Topographic Wetness Index - TWI) (Figura 3G), índice de escoamento superficial (Figura $3 \mathrm{H}$ ), distância dos rios (Figura 3l), aspecto (Figura 3J), uso e cobertura do solo (Figura 3K) e geologia (Figura $3 \mathrm{~L}$ ) - foram considerados para a estimativa do Índice de Suscetibilidade à Inundação (FSI) para a unidade hidrográfica do Riacho Fundo. Os mapas de cada um dos fatores, incluindo os índices estão na Figura 3.

A maior parte da área consiste em uma porcentagem de declividade de $8-20 \%$, conforme Figura 3A. Essa categoria se localiza em maior quantidade na região noroeste do mapa, na região do Vicente Pires. As regiões com mais de $75 \%$ de inclinação encontram-se na região central e centro-oeste da unidade hidrográfica. Espera-se que as regiões de declive mais acentuada possuam um maior potencial de escoamento.

O fator de curvatura (Figura 3B) da unidade hidrográfica mostra áreas predominantemente planas e côncavas e que, praticamente, não há áreas onde a convexidade é proeminente. Com relação ao fator aspecto, o direcionamento dos 
pixels é condizente com a direção do curso da hidrografia. $O$ fator hipsometria (Figura $3 \mathrm{C}$ ) encontra-se com uma variação de 265 metros entre o ponto mais alto da unidade hidrográfica, que atinge o patamar de $1.275 \mathrm{~m}$, e o ponto mais baixo da unidade, de $1.005 \mathrm{~m}$. As áreas mais altas encontram-se ao norte, percorrendo toda a direção leste até 0 ponto sul da unidade hidrográfica. $\mathrm{O}$ fator distância (Figura 3I) dos rios mostra uma gradação da distância a partir do rio, de valor zero, até o ponto mais distante do rio, que está a 4.343,28 m e se localiza na região do extremo sul do mapa. Essa região é um misto de área urbana e vegetação natural de cerrado.

O fator SPI (Figura 3F) concentra-se ao longo do leito do rio e, em seu ponto mais alto, o índice indica um valor de 14.205 , e, no restante da unidade, encontram-se os valores mais baixos. Geralmente, áreas com SPI de valores mais baixos são regiões mais suscetíveis à inundação. Isso é devido ao fato da maioria das regiões com alto valor de SPI estarem localizadas na declividade das encostas e em áreas íngremes, onde as inundações não ocorrem (MOJADDADI et al., 2017). As áreas com menor valor de capacidade de STI (Figura 3F) estão localizadas nas áreas mais planas, portanto, com maior probabilidade a inundação. Essas áreas se concentram nos leitos dos rios e córregos da unidade hidrográfica, pois são áreas de depósito de sedimentos e de intenso trânsito dessa sedimentação. As áreas de menor valor de STI, que compreendem a maior parte da bacia, mostram que há menor suscetibilidade de inundação.

Quanto ao fator TWI (Figura 3G), os maiores valores encontram-se nos leitos dos rios e nas áreas planas da unidade hidrográfica, denotando que essas áreas possuem uma concentração de umidade maior que as áreas de maior elevação, côncavas ou convexas.

$O$ fator TRI (Figura 3E) evidencia seus maiores valores nas áreas de encosta da unidade hidrográfica, locais de declividade mais íngreme e de escoamento das águas superficiais do terreno, onde irão desembocar nos rios e córregos da unidade. Essas áreas apresentam maior irregularidade topográfica no terreno.

O fator de escoamento superficial (Figura $3 \mathrm{H})$ demonstra que os valores intermediários desse índice se encontram nas áreas de maior elevação, havendo um rápido aumento nos valores na medida em que há o aumento da declividade e a diminuição da elevação, sendo que os valores mais altos encontram-se nas encostas presentes na unidade hidrográfica.

O fator uso e cobertura do solo (Figura 3K) é o fator principal de influência no modelo. Tal dado mostra que cerca de $80 \%$ da área de unidade hidrográfica é composta da classe área urbana, que é uma das classes que mais contribui para a inundação em uma localidade.

A geologia da unidade (Figura $3 \mathrm{~L}$ ) é composta por três tipos de rochas e mostra-se muito influente na determinação de suscetibilidade à inundação. Esse fator influencia a infiltração da água da chuva, recarregando os lençóis freáticos da bacia hidrográfica. Áreas mais permeáveis favorecem o processo de infiltração, porém, ressalta-se que as áreas de maior impermeabilização do solo têm a influência do fator geológico anulado com relação à permeabilidade e intensifica 0 processo de escoamento superficial, principalmente onde as declividades são altas e médias e a curvatura é côncava (REIS et al., 2012).

\section{Aplicação do modelo de Razão Frequência (FR)}

A relação entre a ocorrência de inundação e cada um dos fatores condicionantes foi estabelecida por meio da análise de FR. O modelo atribui a cada fator de influência um peso baseado na quantidade de pixels de cada fator presente nas áreas com histórico de inundação já previamente mapeadas. A ordem dos fatores de influência foi: (i) Uso e Cobertura do Solo (maior influência); (ii) Geologia; (iii) Curvatura; (iv) SPI; (v) TRI; (vi) Escoamento Superficial; (vii) Elevação; (viii) Distância do rio; (ix) STI; (x) Declividade; (xi) TWI; e (xii) Aspecto (Tabela 2).

Para mapear os locais de inundação na área de estudo é importante explicar a correlação entre as inundações $\mathrm{e}$ os diferentes fatores condicionantes. O modelo de probabilidade de FR para cada fator de condicionante foi calculado conforme mostrado na Tabela 3.

Nos resultados da aplicação do método FR, $99 \%$ dos pixels do fator declividade se encontram na classe de declividade até $14^{\circ}$, mostrando que inundações são mais propícias a ocorrerem em áreas de baixo declive. A integração desses dados com o fator hipsometria evidencia um valor de FR mais alto para a classe entre 1.113 a 1.160 $\mathrm{m}$, sugerindo que as inundações ocorrem em áreas de baixa declividade e de altitude intermediária nesta unidade hidrográfica. $O$ fator aspecto mostra que a correlação entre a 
inundação e esse fator é mais forte na região sul e sudeste da unidade, por apresentar maior valor de $F R$, indicando que a maioria dos pixels dos pontos de inundação aponta para essa direção. A região sudeste é a direção para onde corre 0 fluxo da hidrografia e é a região com mais pontos de inundação.

O fator TWI apresenta valor de FR $>1$ para a primeira e a segunda classe, revelando que a correlação entre o fator inundação tende a ocorrer nas regiões de menor valor de TWI de classes, enquanto as regiões de maior valor de classe decrescem de importância.

O fator STI evidenciou que praticamente somente a primeira classe possui valor $\mathrm{FR}=1$. Quanto ao fator distância dos rios, os resultados mostram que a primeira e a segunda classe, as de menores distâncias, têm maior influência de inundação por ter um valor $\mathrm{FR}>1$ e ser o maior valor entre as classes. Esse fator condicionante tem um valor $R^{2}=0,62$, assinalando uma relação de força intermediária entre as classes e o valor de FR. Isso indica que a proximidade ao leito do rio é um fator de risco à inundação.

Observando o mapa de uso e cobertura do solo na unidade, notam-se áreas urbanas às margens dos principais rios e córregos. $O$ distanciamento dos cursos d'águas respeita as áreas de proteção permanente na unidade, que influencia diretamente na contenção dos transbordos dos rios e, portanto, nas inundações e enchentes.

O fator de escoamento superficial também apresenta alta contribuição para a inundação no local, com uma relação entre as classes em áreas inundadas, onde seu fator de maior influência ocorre nas áreas de maior urbanização, indicando uma correlação com a impermeabilidade do terreno. Essa impermeabilidade mostra-se relacionada ao fator de urbanização e, por sua vez, influencia diretamente no escoamento superficial. O maior valor de FR está na classe de valores entre 1,64 e 2,09.

Para mapear os locais de inundação na área de estudo é importante explicar a correlação entre as inundações e os diferentes fatores de condição. O modelo de probabilidade de FR para cada fator de condicionante foi calculado conforme mostrado na Tabela 2.

O fator TRI mostra a segunda classe com valor de $\mathrm{FR}>1$, denotando que a maior parte das inundações acontece nesse intervalo de valores. A determinação do fator TRI com a inundação é de $R^{2}=0,82$, revelando uma forte relação entre as áreas inundadas e o FR. As áreas de inundação encontram-se em regiões de baixo valor de TRI, sugerindo que quanto menor a rugosidade do terreno, mais propício e influente ele é para o fenômeno da inundação, que tende a acontecer em locais planos. O fator SPI mostrou, assim como o fator TWI, que somente os valores mais baixos do fator contribuem para a inundação e que possuem grande potencial de inundação as áreas mais baixas do terreno. A segunda classe de valores apresentou um valor de $F R>1$, indicando que as inundações tendem a acontecer mais nesse intervalo de valores, enquanto as classes de valores superiores não influenciam nas inundações.

$O$ fator curvatura teve um valor de FR $>1$ para áreas de inundação que estão na classe plana do terreno, assinalando que inundações só podem ocorrer em áreas planas. $O$ fator geologia mostrou-se o segundo fator de maior influência no modelo. $\mathrm{O}$ valor $\mathrm{FR}>1$ está em locais onde há a presença de ardósia, enquanto $25,53 \%$ estão em área de rocha denominada ritmito.

A relação entre cada fator condicionante $e$ seu valor de FR é apresentada na Tabela 3.

O fator mais fortemente influente é o fator de uso e cobertura de solo. Esse fator mostra que o valor $\mathrm{FR}>1$ está na classe denominada área urbana, com uma correlação $R^{2}=0,98$ e maior peso de predição (Prediction Rate - PR). Essa é a condição mais importante para a ocorrência de inundações, de acordo com este estudo, com a literatura e com a observação dos locais, na unidade hidrográfica aqui pesquisada. A presença de área urbana impermeabiliza o solo, impedindo a infiltração de água no lençol freático.

Integrando os fatores mais influentes para a ocorrência de inundação, formou-se o mapa da Figura 4. Nota-se que áreas onde há alto grau de inclinação da declividade e a presença de área impermeabilizada na região, há uma maior geração de escoamento superficial e aumento da velocidade da movimentação da água. Essa água irá se depositar nas regiões planas e de menor elevação e, a depender do grau de permeabilidade da rocha, que compõe a geologia do local e de outros fatores marginais, como o fator TWI, TRI, SPI e STI, áreas de inundação podem ser geradas.

A validação do mapa de suscetibilidade com dado de treino apresentou um resultado de AUC de $85,75 \%$ e um resultado de $93,53 \%$, mostrando que, para essa unidade hidrográfica, os pontos de teste favoreceram um mapa de suscetibilidade 
mais preciso.

Figura 3. Mapas dos fatores de influência da Bacia do Riacho Fundo (DF)
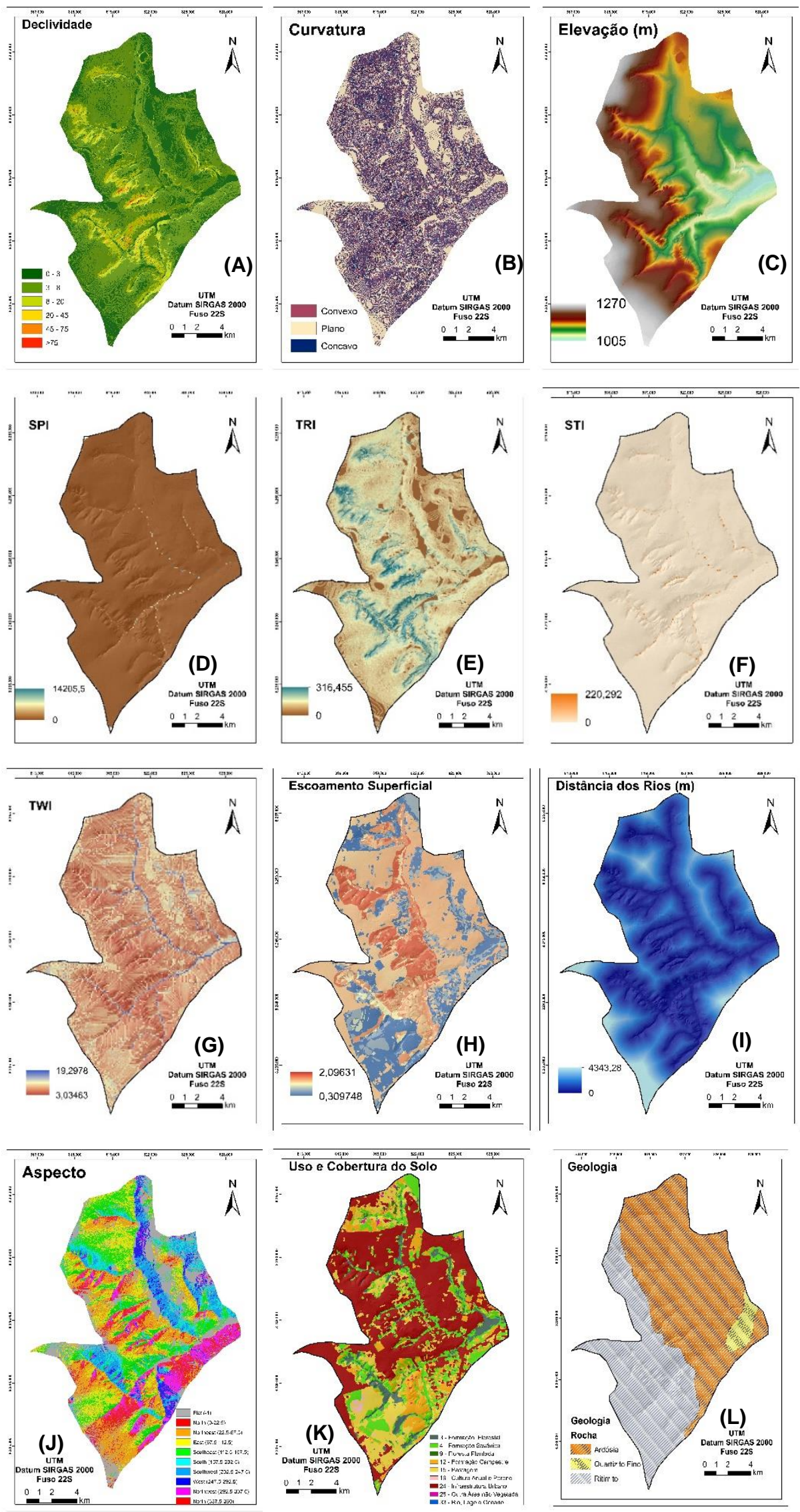

Fonte: Os autores. 
Tabela 2 - Resultados da razão frequência de cada fator

\begin{tabular}{|c|c|c|c|c|c|c|}
\hline $\begin{array}{c}\text { Fator } \\
\text { Condicionante }\end{array}$ & Classes & $\begin{array}{c}\text { Número } \\
\text { de } \\
\text { pixels }\end{array}$ & $\begin{array}{c}\text { \% de } \\
\text { píxels } \\
\text { por } \\
\text { classe }\end{array}$ & $\begin{array}{c}\text { Número de } \\
\text { píxels } \\
\text { inundados }\end{array}$ & $\begin{array}{l}\text { \% de píxels } \\
\text { inundados }\end{array}$ & $\begin{array}{l}\text { Frequencia } \\
\text { Razão (FR) }\end{array}$ \\
\hline \multirow{5}{*}{$\begin{array}{c}\text { Declividade } \\
\text { (Graus) }\end{array}$} & $<7$ & 1202733 & $94,2 \%$ & 41713 & $91,7 \%$ & 0,97 \\
\hline & 7 a 14 & 63471 & $5,0 \%$ & 3498 & $7,7 \%$ & 1,55 \\
\hline & 14 a 22 & 9105 & $0,7 \%$ & 270 & $0,6 \%$ & 0,83 \\
\hline & 22 a 29 & 1574 & $0,1 \%$ & 25 & $0,1 \%$ & 0,45 \\
\hline & $>29$ & 379 & $0,0 \%$ & 2 & $0,0 \%$ & 0,15 \\
\hline \multirow{3}{*}{ Curvatura } & Côncavo & 519 & $0,0 \%$ & 2 & $0,0 \%$ & 0,11 \\
\hline & Plano & 1276843 & $99,6 \%$ & 45453 & $99,9 \%$ & 1,00 \\
\hline & Convexo & 5064 & $0,4 \%$ & 53 & $0,1 \%$ & 0,29 \\
\hline \multirow{13}{*}{ Aspecto } & Flat $(-1)$ & 374370 & $29,3 \%$ & 7065 & $15,5 \%$ & 0,53 \\
\hline & North $(0-22.5)$ & 190552 & $14,9 \%$ & 2015 & $4,4 \%$ & 0,30 \\
\hline & Northeast (22.5- & & & & & \\
\hline & $67.5)$ & 228530 & $17,9 \%$ & 11612 & $25,5 \%$ & 1,43 \\
\hline & East (67.5-112.5) & 134662 & $10,5 \%$ & 4953 & $10,9 \%$ & 1,03 \\
\hline & Southeast (112.5- & & & & & \\
\hline & 157.5) & 82905 & $6,5 \%$ & 6062 & $13,3 \%$ & 2,05 \\
\hline & South (157.5-202.5) & 78692 & $6,2 \%$ & 5842 & $12,8 \%$ & 2,08 \\
\hline & Southwest (202.5- & & & & & \\
\hline & 247.5) & 62597 & $4,9 \%$ & 4119 & $9,1 \%$ & 1,85 \\
\hline & West (247.5-292.5) & 55078 & $4,3 \%$ & 1677 & $3,7 \%$ & 0,85 \\
\hline & Northwest (292.5- & & & & & \\
\hline & $337.5)$ & 69876 & $5,5 \%$ & 2163 & $4,8 \%$ & 0,87 \\
\hline \multirow{5}{*}{ Elevação (m) } & $1.005-1.066$ & 160502 & $12,5 \%$ & 1781 & $3,9 \%$ & 0,31 \\
\hline & $1.066-1.113$ & 406990 & $31,7 \%$ & 14989 & $32,9 \%$ & 1,04 \\
\hline & $1.113-1.160$ & 304998 & $23,8 \%$ & 20361 & $44,7 \%$ & 1,88 \\
\hline & $1.160-1.208$ & 262163 & $20,4 \%$ & 8377 & $18,4 \%$ & 0,90 \\
\hline & $1.208-1.270$ & 147773 & $11,5 \%$ & 0 & $0,0 \%$ & 0,00 \\
\hline \multirow{5}{*}{$\begin{array}{l}\text { Distância dos } \\
\text { Rios }(m)\end{array}$} & $0-340$ & 950056 & $74,0 \%$ & 34575 & $76,0 \%$ & 1,03 \\
\hline & $340-783$ & 277984 & $21,7 \%$ & 10547 & $23,2 \%$ & 1,07 \\
\hline & $783-1.328$ & 41577 & $3,2 \%$ & 386 & $0,8 \%$ & 0,26 \\
\hline & $1.328-2.197$ & 11586 & $0,9 \%$ & 0 & $0,0 \%$ & 0,00 \\
\hline & $2.197-4.343$ & 2476 & $0,2 \%$ & 0 & $0,0 \%$ & 0,00 \\
\hline \multirow{5}{*}{$S P I$} & $0-445$ & 1274557 & $99,7 \%$ & 45336 & $99,6 \%$ & 1,00 \\
\hline & $445-1.615$ & 2848 & $0,2 \%$ & 172 & $0,4 \%$ & 1,70 \\
\hline & $1.615-3.063$ & 456 & $0,0 \%$ & 0 & $0,0 \%$ & 0,00 \\
\hline & $3.063-5.737$ & 192 & $0,0 \%$ & 0 & $0,0 \%$ & 0,00 \\
\hline & $5.737-14.205$ & 128 & $0,0 \%$ & 0 & $0,0 \%$ & 0,00 \\
\hline \multirow{5}{*}{ STI } & $0-7$ & 1267989 & $99,2 \%$ & 45252 & $99,4 \%$ & 1,00 \\
\hline & $7,77-30,23$ & 7688 & $0,6 \%$ & 236 & $0,5 \%$ & 0,86 \\
\hline & $30,23-65,65$ & 1536 & $0,1 \%$ & 20 & $0,0 \%$ & 0,37 \\
\hline & $65,65-120,08$ & 840 & $0,1 \%$ & 0 & $0,0 \%$ & 0,00 \\
\hline & $120,08-220,29$ & 128 & $0,0 \%$ & 0 & $0,0 \%$ & 0,00 \\
\hline \multirow{5}{*}{$T W I$} & $3,03-6,41$ & 312510 & $24,4 \%$ & 12258 & $26,9 \%$ & 1,10 \\
\hline & $6,41-8,32$ & 766320 & $60,0 \%$ & 28196 & $62,0 \%$ & 1,03 \\
\hline & $8,32-10,56$ & 161142 & $12,6 \%$ & 4085 & $9,0 \%$ & 0,71 \\
\hline & $10,56-14,13$ & 26361 & $2,1 \%$ & 882 & $1,9 \%$ & 0,94 \\
\hline & $14,13-19,29$ & 11848 & $0,9 \%$ & 87 & $0,2 \%$ & 0,21 \\
\hline$T R I$ & $0-49,64$ & 338022 & $26,1 \%$ & 6035 & $13,3 \%$ & 0,51 \\
\hline
\end{tabular}


Revista Eletrônica de Gestão e Tecnologias Ambientais (GESTA)

\begin{tabular}{|c|c|c|c|c|c|c|}
\hline & $49,64-85,62$ & 854674 & $65,9 \%$ & 37460 & $82,3 \%$ & 1,25 \\
\hline & $85,62-116,65$ & 94331 & $7,3 \%$ & 1947 & $4,3 \%$ & 0,59 \\
\hline & $116,65-158,84$ & 9510 & $0,7 \%$ & 66 & $0,1 \%$ & 0,20 \\
\hline & $158,84-316,45$ & 642 & $0,0 \%$ & 0 & $0,0 \%$ & 0,00 \\
\hline \multirow{5}{*}{$\begin{array}{c}\text { Escoamento } \\
\text { Superficial }\end{array}$} & $0,30-0,55$ & 285376 & $22,3 \%$ & 497 & $1,1 \%$ & 0,05 \\
\hline & $0,55-0,91$ & 145392 & $11,3 \%$ & 1042 & $2,3 \%$ & 0,20 \\
\hline & $0,91-1,33$ & 84035 & $6,6 \%$ & 4052 & $8,9 \%$ & 1,36 \\
\hline & $1,33-1,64$ & 635795 & $49,6 \%$ & 27427 & $60,3 \%$ & 1,22 \\
\hline & $1,64-2,09$ & 131385 & $10,2 \%$ & 12490 & $27,4 \%$ & 2,68 \\
\hline \multirow{9}{*}{$\begin{array}{c}\text { Uso e } \\
\text { Cobertura do } \\
\text { solo }\end{array}$} & $\begin{array}{l}3 \text { - Formação } \\
\text { Florestal } \\
4 \text { - Formação }\end{array}$ & 289994 & $23,3 \%$ & 2090,00014 & $4,7 \%$ & 0,20 \\
\hline & $\begin{array}{l}\text { Savânica } \\
9 \text { - Floresta }\end{array}$ & 2053 & $0,2 \%$ & 0 & $0,0 \%$ & 0,00 \\
\hline & $\begin{array}{l}\text { Plantada } \\
12 \text { - Formação }\end{array}$ & 125985 & $10,1 \%$ & 88,000006 & $0,2 \%$ & 0,02 \\
\hline & Campestre & 207808 & $16,7 \%$ & 348,000024 & $0,8 \%$ & 0,05 \\
\hline & 15 - Pastagem & 6247 & $0,5 \%$ & 49,000003 & $0,1 \%$ & 0,22 \\
\hline & $\begin{array}{l}19 \text { - Cultura Anual e } \\
\text { Perene } \\
24 \text { - Infraestrutura }\end{array}$ & 0 & $0,0 \%$ & 0 & $0,0 \%$ & 0,00 \\
\hline & Urbana & 612608 & $49,2 \%$ & 41591,0029 & $94,2 \%$ & 1,91 \\
\hline & $\begin{array}{l}\text { Vegetada } \\
33 \text { - Rio, Lago e }\end{array}$ & 0 & $0,0 \%$ & 0 & $0,0 \%$ & 0,00 \\
\hline & Oceano & 252 & $0,0 \%$ & 0 & $0,0 \%$ & 0,00 \\
\hline \multirow{3}{*}{ Geologia } & MNPps & 505748 & $39,4 \%$ & 11620 & $25,5 \%$ & 0,65 \\
\hline & MNPpr3 & 735199 & $57,3 \%$ & 33886 & $74,5 \%$ & 1,30 \\
\hline & MNPpa & 42732 & $3,3 \%$ & 2 & $0,0 \%$ & 0,00 \\
\hline
\end{tabular}

Fonte: Os Autores.

Tabela 3 - Relação entre áreas inundadas e o valor FR

\begin{tabular}{l|l|l}
\hline Fator Condicionante & Regressão Linear & $\mathbf{R}^{\mathbf{2}}$ \\
\hline Aspecto & $\mathrm{y}=8 \mathrm{E}-05 \mathrm{x}+0,837$ & 0,12 \\
\hline TWI & $1 \mathrm{E}-05 \mathrm{x}+0,4223$ & 0,35 \\
\hline Declividade & $\mathrm{y}=8 \mathrm{E}-06 \mathrm{x}+0,719$ & 0,07 \\
\hline STI & $1 \mathrm{E}-05 \mathrm{x}+0,4223$ & 0,44 \\
\hline Distância do rio & $\mathrm{y}=8 \mathrm{E}-05 \mathrm{x}+0,837$ & 0,62 \\
\hline Elevação & $\mathrm{y}=8 \mathrm{E}-05 \mathrm{x}+0,837$ & 0,94 \\
\hline $\begin{array}{l}\text { Escoamento } \\
\text { superficial }\end{array}$ & $3 \mathrm{E}-05 \mathrm{x}+0,2624$ & 0,21 \\
\hline TRI & & \\
\hline SPI & $3 \mathrm{E}-05 \mathrm{x}+0,2624$ & 0,82 \\
\hline Curvatura & $1 \mathrm{E}-05 \mathrm{x}+0,4223$ & 0,11 \\
\hline Geologia & $\mathrm{y}=8 \mathrm{E}-06 \mathrm{x}+0,719$ & 0,96 \\
\hline Uso e cobertura & $\mathrm{y}=4 \mathrm{E}-05 \mathrm{x}+0,0465$ & 0,96 \\
\hline Fonte: Os Autors & $\mathrm{y}=4 \mathrm{E}-05 \mathrm{x}+0,0465$ & 0,98 \\
\hline
\end{tabular}

Fonte: Os Autores. 
Figura 4. Mapa de Suscetibilidade à inundação da Bacia do Riacho Fundo (DF)

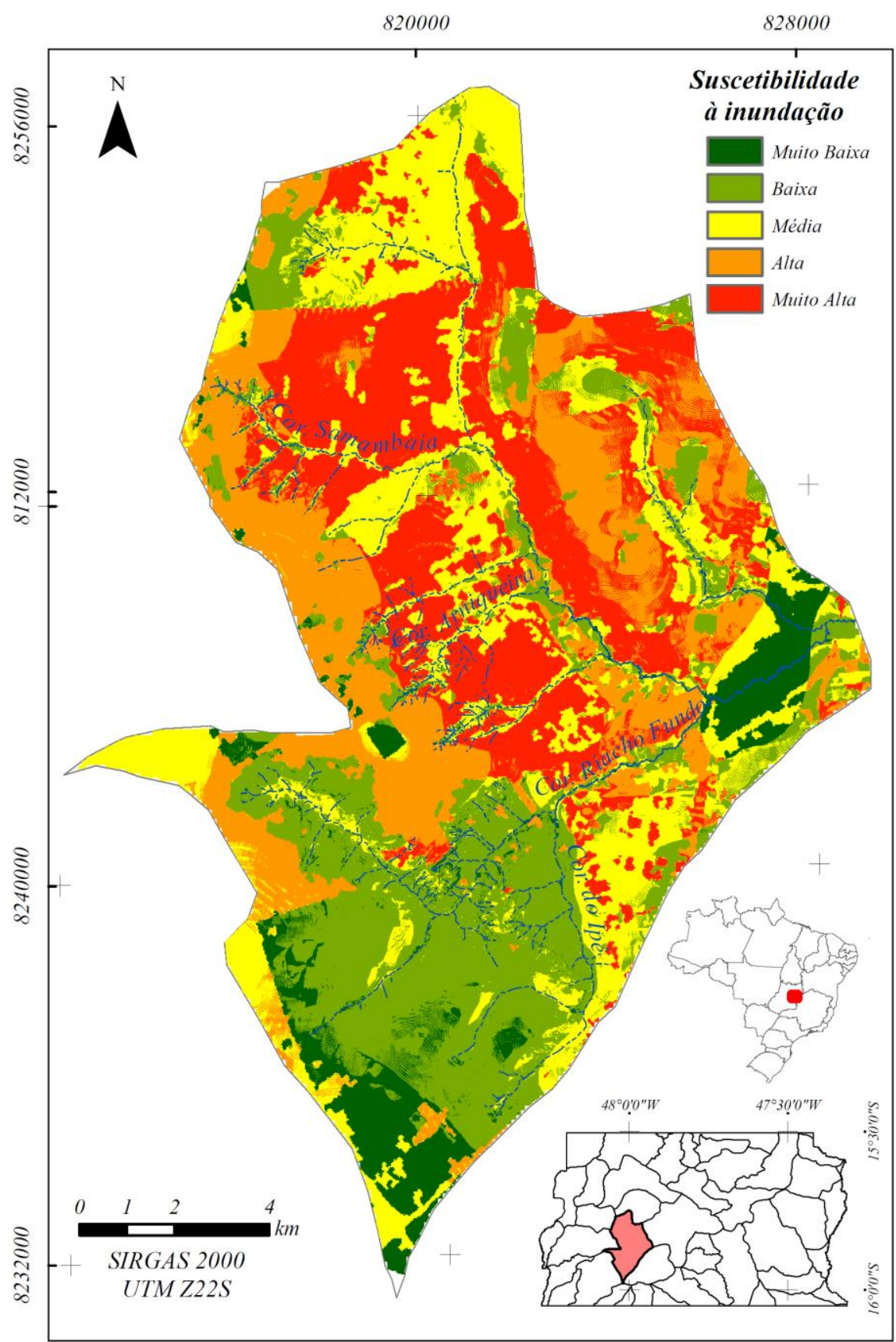

Fonte: Os autores.

Vicente Pires

A devastação e prejuízo também ocorrem nas áreas por onde o fluxo do escoamento passa, e não apenas nas áreas onde se depositam. Esse parece ser o problema que ocorre com a região do Vicente Pires, centro norte da bacia estudada. A Figura 5 mostra um recorte da região no mapa de suscetibilidade, e indica que é uma área que apresenta o índice muito alto, como predominante aos eventos de inundação.

As áreas onde o fluxo de escoamento é alto se

caracterizam por elevada urbanização e declividade acentuada. Há um grau muito alto de impermeabilização do solo; e há um projeto, ainda em andamento, de bacias de contenção nos pontos de maior ocorrência de inundações.

$\mathrm{Na}$ Figura 5, foram inseridas as bacias de detenção já construídas no Vicente Pires, e percebe-se que a localização destas são a jusante das mais críticas à inundação; o que indica o posicionamento inadequado das mesmas. Na região, há problemas de invasão de terra e grilagem, o que comprova a existência de ocupações em Área de Proteção Permanente 
(APP), próximas ao córrego do Vicente Pires e do córrego Samambaia. A instalação das bacias de detenção auxilia na preservação dos corpos hídricos receptores, com lançamentos de vazões menores, porém, não são capazes de aliviar a pressão nos sistemas de drenagem urbana para prevenção de inundações.

\section{Figura 5. Mapa de suscetibilidade à inundação na região do Vicente Pires com a localização das bacias de detenção}

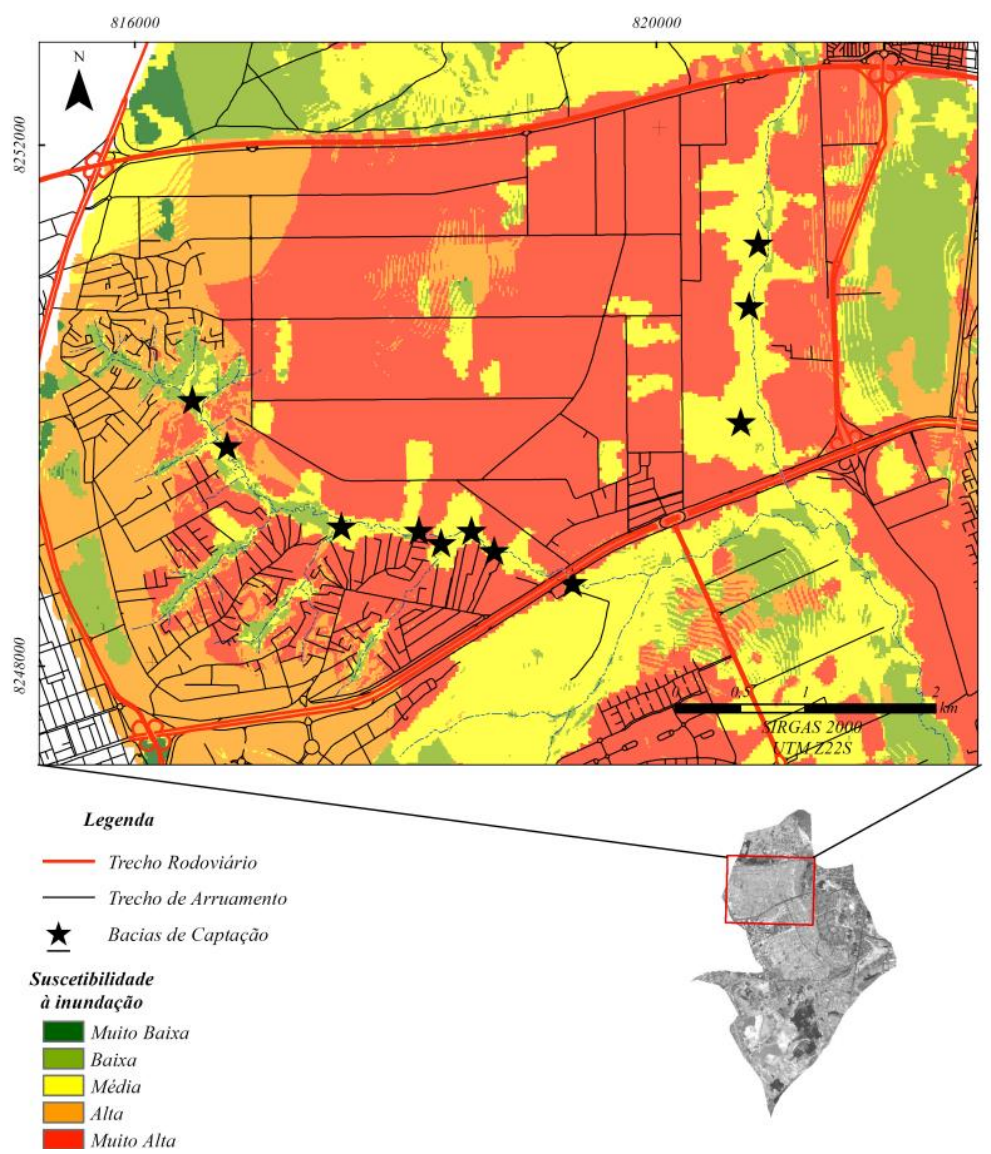

Fonte: Os autores.

\section{CONCLUSÃO}

O método RF utilizado para construir o mapa de suscetibilidade à inundação mostrou-se representativo da situação dos casos desse fenômeno na Bacia do Riacho Fundo e, especificamente, na região do Vicente Pires, apontando as áreas suscetíveis a esse impacto ambiental.

Os fatores condicionantes que mais influenciaram o modelo de inundação foram - Uso e Cobertura do Solo, a geologia do local e a curvatura. Tais fatores mostram que, para essa unidade hidrográfica, a urbanização tem um efeito determinante nos locais de inundação, devido à alta impermeabilização do solo que a urbanização trás. A geologia indica que 0 nível de penetração da água no solo é bastante dependente do tipo de rocha e que inundações ocorrem a montante em áreas planas da unidade. Os fatores de aspecto do terreno e TWI têm menor influência no modelo.

As áreas de menor risco de inundação encontram-se nas regiões de remanescentes de vegetação nativa, como formação campestre, formação savânica e agricultura, as quais se localizam ao sul da unidade hidrográfica. A região onde se encontra uma mancha de quartzito apresentou uma baixa suscetibilidade à inundação. As regiões de maior risco de inundação estão localizadas nas regiões de alta urbanização, com declividade 
acentuada e alto escoamento superficial devido à impermeabilização do solo, no qual a implantação de áreas verdes e permeáveis pode ajudar na redução de enxurradas e inundações na região, pois essas áreas retêm o escoamento superficial, reduzindo a velocidade do escoamento e permitindo a infiltração da água superficial. Com isso, minimiza-se 0 efeito das áreas de baixa altitude e próximas aos córregos, as quais, também, representam locais de alta suscetibilidade à inundação. As áreas de suscetibilidade média ou intermediária localizam-se em regiões moderadamente urbanizadas, com declividade e fator TRI acentuadas, porém, são pontos sem histórico de inundação nos últimos dez anos e se encontram em locais de maior elevação.

O mapa de suscetibilidade à inundação deve ser elaborado antes da construção das Bacias de Detenção, a fim de otimizar suas funções, não só para amortecimento de vazões, mas, também, para diminuir as inundações dentro das áreas urbanas.

\section{Agradecimentos}

Ao professor José Eloi Campos por disponibilizar os shapes de geologia da unidade hidrográfica; ao professor Sérgio Koide, à mestranda Daniela Carvalho e ao PTARH-UnB por dispor parte dos dados de precipitação de três pluviômetros usados neste trabalho; e ao Instituto de Geociências por franquear o Laboratório de Sensoriamento Remoto, seu equipamento de processamento dos dados e a utilização do software ArcGIS.

\section{REFERÊNCIAS}

AGÊNCIA BRASÍLIA. Subsecretaria de Divulgação Secretaria de Estado de Comunicação do DF. 2019. Disponível em: https://www.agenciabrasilia.df.gov.br/2019/06/08 lagoas-de-captacao-vao-dar-vazao-as-aguasde-chuvas-em-vicente-pires/ . Acesso: 31 ago. 2020.

ALI, S. A.; PARVIN, F.; PHAM, Q. B.; VOJTEK, M.; VOJTEKOVÁ, J.; COSTACHE, R.; LINH, N.
T. T.; NGUYEN, H. Q.; AHMAD, A.; GHORBANI, M. A. GIS-based comparative assessment of flood susceptibility mapping using hybrid multi-criteria decision-making approach, naïve Bayes tree, bivariate statistics and logistic regression: A case of Topla basin, Slovakia. Ecological Indicators, 117 [Online] 1066202. 2020. Disponível em: https://doi.org/10.1016/i.ecolind.2020.106620. Acesso em: 22 ago. 2020.

AQUINO, I. G.; ROIG, H. L.; OLIVEIRA, E. S.; GARNIER, J.; GUIMARÃES, E. M.; KOIDE, S. Variação temporal da descarga sólida em suspensão e identificação de minerais a partir de aperfeiçoamento de método de amostragem automática no Córrego Riacho Fundo, Brasília, Distrito Federal. Geol. USP, Sér. cient., USP, v. 18 , n. 2, p. 17-185, 2018.

ARAÚJO NETO, J. R. de; PALÁCIO, H. A. de Q.; De ANDRADE, E. M.; DOS SANTOS, J. C. N.; PINHEIRO, E. A. R. Optimization of the cuver number (cn-scs) for different management in a semiarid region, Ceará, Brasil. Irriga,

Botucatu, Edição Especial, p. 264-279, 2012. BUI, D. T.; TSANGARATOS, P.; NGO, P. T.; PHAM, T. D.; PHAM, B. T. Flash flood susceptibility modeling using an optimized fuzzy rule based feature selection technique and tree based ensemble methods. Science of the Total Environment, n. 668, p. 1038-1054, 2019. Disponível em: https://doi.org/10.1016/j.scitotenv.2019.02.422. Acesso em: 22 ago. 2020.

CAMPOS, J. E. G.; DARDENNE, M. A.; FREITAS-SILVA, F. H.; MARTINS-FERREIRA, M. A. C. Geologia do Grupo Paranoá na porção externa da Faixa Brasília. Brazilian Journal of Geology [Online], São Paulo, v. 43, n. 3, p. 461476, set. 2013. DOI: $10.5327 / Z 2317-$ 48892013000300004 Disponível em: http://bjg.siteoficial.ws/2013/n.3/d.pdf. Acesso em: 15 ago. 2020.

CANIANI D.; PASCALE S.; SDAO F.; SOLE A. Neural networks and landslide susceptibility: a case study of the urban area of Potenza. Nat Hazards v. 45, n. 1, p. 55-72, 2008.

CEOLIN, L.F.; COSTA, M.E.L.; KOIDE, S. Estudo hidráulico-hidrológico de uma bacia de detenção em Vicente Pires/DF. In: SIMPÓSIO BRASILEIRO DE RECURSOS HIDRÍCOS, 23., 2019, Foz do Iguaçu. Anais... Foz do Iguaçu- 
PR: Associação Brasileira de Recursos Hídricos, 2019.

DANO, U.; BALOGUN, A.-L.; MATORI, A.-N.; WAN YUSOUF, K.; RIMI ABUBAKAR, I.; SAID MOHAMED, M.; PRADHAN, B. Flood susceptibility mapping using GIS-based analytic network process: a case study of Perlis, Malaysia. Water, v. 11, n. 3, p. 615, 2019. Disponível em: https://doi.org/10.3390/w11030615. Acesso em: 22 ago. 2020.

DE PAULA, A. C. V.; COSTA, M.E.L.; KOIDE, S. Drenagem urbana - análise de problemas de novos loteamentos - estudo de caso no setor habitacional Vicente Pires. In. ENCONTRO NACIONAL DE ÁGUAS URBANAS, 11., 2017, Belo Horizonte. Anais... Belo Horizonte-MG: Associação Brasileira de Recursos Hídricos, 2017.

\section{EMBRAPA. Sistema Brasileiro de} Classificação de Solos. Humberto Gonçalves dos Santos [et al.]. - 5. ed., rev. e ampl. Brasília, DF : Embrapa, 2018. ISBN 978-857035-800-4

ESRI - Environmental Systems Research Institute. ArcGIS Desktop: Release 10. Redlands, CA: Environmental Systems Research Institute, 2018.

HAGHIZADEH, A.; SIAHKAMARI, S.; ZEINIVAND, H.; TAHMASEBIPOUR, N.; RHAMTI, O. Spatial prediction of floodsusceptible areas using frequency ratio and maximum entropy models. Geocarto International, v. 33, n. 9 p. 927-941, 2017. DOI: 10.1080/10106049.2017.1316780.

HIPÓLITO, M. T.; COSTA, T. C. C.; BARROS, L. C.; VIANA, A. A. O. N. Alocação de barraginhas com uso de modelagem hidrológica e geoprocessamento. Sete Lagoas: Embrapa Milho e Sorgo, 2019. 28 p. : il. -- (Boletim de Pesquisa e Desenvolvimento / Embrapa Milho e Sorgo, ISSN 1679-0154; 190).

HONG. H.; PRADHAN, B.; SAMEEN, M. I.; CHEN, W.; XU, C. Spatial prediction of rotational landslide using geographically weighted regression, logistic regression, and support vector machine models in Xing Guo area (China), Geomatics, Natural Hazards and Risk, v. 8, n. 2, p. 1997-2022 2017. DOI: 10.1080/19475705.2017.1403974
KHOSRAVI, K.; SHAHABIB, H.; PHAM, B. T.; ADAMOWSKID, J.; SHIRZADIE, A.; PRADHANF, B.; DOUH, J.; HAI-BANG, L.; GRÓFJ, G.; HOK, H. L.; HONGL, H.; CHAPI, K. A comparative assessment of flood susceptibility modeling using multi-criteria decision-making analysis and machine learning methods.

Journal Of Hydrology, [s.I.], v. 573, p.311-323, 2019. Disponível em: https://doi.org/10.1016/j.jhydrol.2019.03.073. Acesso em: 22 ago.2020.

; NOHANI, E.; MAROUFINIA, E.; POURGHASEMI, H. R. A GIS-based flood susceptibility assessment and its mapping in Iran: a comparison between frequency ratio and weights-of-evidence bivariate statistical models with multi-criteria decision-making technique. Natural Hazards, n. 83, p. 947-987, 2016. DOI 10.1007/s11069-016-2357-2.

KIA M.B.; PIRASTEH, S.; PRADHAN, B.; MAHMUD, A.R.; SULAIMAN, W.N.A.; MORADI, A. An artificial neural network model for flood simulation using GIS: Johor River Basin Malaysia. Environmental Earth Scientific, v. 67, n. 1, p. 251-264, 2012.

KORZENIOWSKA, K.; PFEIFER, N.; LANDTWING, S. Mapping gullies, dunes, lava fields, and landslides via surface roughness, Geomorphology, n. 301, p. 53-67, 2017. Doi:10.1016/j.geomorph.2017.10.011

LIMA, I. F.; FERNANDES, N. F.; VARGAS JUNIOR, E. A. Análise morfométrica em bacias afetadas por fluxos de detritos na Região Serrana do Rio de Janeiro. Rev. Bras. Geomorfol. (Online), São Paulo, v. 21, n. 2, p. 399-419, abr./jun. 2020. Disponível em: http://dx.doi.org/10.20502/www.ugb.org.br rbg.v21i2.1515. Acesso em: 30 ago. 2020. MANTOVANI, J. R.; BACANI, V. M. Uma proposta metodológica de mapeamento de áreas suscetíveis à inundação e/ ou alagamento na bacia hidrográfica do córrego Indaiá-MS. Geousp - Espaço e Tempo (Online), v. 22, n. 3, p. 687-706, dez. 2018. ISSN 2179-0892.

MELESSE, A.M.; SHIH, S.F. Spatially distributed storm runoff depth estimation using Landsat images and GIS/ Computers and Electronics in Agriculture, v. 37, p. 173-183, 2002.

MIRANDA, N. M. G.; CAPRARIO, J.; MARTINI, L. C. P.; FINOTTI, A. R. Processo hierárquico analítico (AHP) em modelagem espacial da vulnerabilidade à inundação em ambientes 
mistos. Anuário do Instituto de Geociências, UFRJ, v. 42, n. 4, p 172-181, 2019. ISSN 01019759 e-ISSN 1982-3908.

MOJADDADI, H.; PRADHAN, B.; NAMPAK, H.; AHMAD, N.; GHAZALI, A. H. Ensemble machine-learning-based geospatial approach for flood risk assessment using multi-sensor remote-sensing data and GIS. Geomatics, Natural Hazards and Risk, v. 8, n. 2, p. 10801102, 2017.

MOORE, I.D.; GRAYSON, R.B.; LADSON, A.R. Digital terrain modelling, a review of hydrological, geomorphological, and biological applications. Hydrol. Process., n. 5, p. 3-30, 1991.

NETO, G. B. S.; BAYMA, A. P.; NETO, S. B.; ROIG, H. L.; MENEZES, P. H. B. J. Análise de suscetibilidade a alagamento na Bacia Hidrográfica do Riacho Fundo - Distrito Federal por meio de sistemas de informação geográfica - SIG. Revista Territorium, n. 24, p. 77-87, 2017. (C) Riscos, ISSN: 0872-8941.

PHAM, B.T.; TIEN BUI, D.; POURGHASEMI, H.R.; INDRA, P.; DHOLAKIA, M.B. Landslide susceptibility assessment in the Uttarakhand area (India) using GIS: a comparison study of prediction capability of naïve bayes, multilayer perceptron neural networks, and functional trees methods. Theor. Appl. Climatol., n. 122, p. 119, 2015.

PRADHAN, B.; ABOKHARIMA, M.H.; JEBUR, M.N.; TEHRANY, M.S. Land subsidence susceptibility mapping at Kinta Valley (Malaysia) using the evidential belief function model in GIS. Nat. Hazards, v. 73, n. 2, p. 1-24, 2014.

; LEE S. Landslide susceptibility assessment and factor effect analysis: backpropagation artificial neural networks and their comparison with frequency ratio and bivariate logistic regression modelling. Environ. Model Softw, v. 25, n. 6, p. 747-759, 2010.

RAHMATI, O.; POURGHASEMI, R. H.; ZEINIVAND, H. Flood susceptibility mapping using frequency ratio and weights-of-evidence models in the Golastan Province, Iran. Geocarto International, v. 31, n. 1, p. 42-70, 2015. DOI:10.1080/10106049.2015.1041559

; ZEINIVAND, H.; BESHARAT,M. Flood hazard zoning in Yasooj region, Iran, using GIS and multi-criteria decision analysis. Geom. Nat.
Haz. Risk, v. 7, n. 3, p. 1000-1017, 2016.

RAMESH, V.; IQBAL, S. S. Urban flood susceptibility zonation mapping using evidential belief function, frequency ratio and fuzzy gamma operator models in gis: a case study of greater Mumbai, Maharashtra, India. Geocarto International [Online], 2020. DOI: 10.1080/10106049.2020. Disponível em: ISSN: 1010-6049 (Print) 1752-0762 (Online) Journal homepage: https://www. tandfonline. com/loi/tgei20

REIS, P. E.; PARIZZI, M. G.; MAGALHÃES, D M.; MOURA, A.C.M.2012. O Escoamento superficial como condicionante de inundações em Belo Horizonte, MG: Estudo de caso da subbacia Córrego de Leitão, Bacia de Ribeirão Arrudas. Geociências, UNESP, v. 31, n. 1, p. 31-46, 2012.

RILEY, S.J.; DE GLORIA, S.D.; ELLIOT, R. A terrain ruggedness index that quantifies topographic heterogeneity. Intermountain Journal of Sciences, n. 5, p. 23-27, 1999.

SAMANTA, R. K.; BHUNIA, G. S.; SHIT, P. K.; POURGHASEMI H.R. Flood susceptibility mapping using geospatial frequency ratio technique: a case study of Subarnarekha River Basin, India. Modeling Earth Systems and Environment [Online], n. 4, p. 395-408, 2018. Disponível em: https://doi.org/10.1007/s40808018-0427-z. Acesso em: 31 ago. 2020.

SANTOS, F.M., LOLLO, J.A., 2016. Cartografia Digital para Estimativa de Escoamento Superficial Visando ao Planejamento Urbano. Eng. Sanit. Ambient., v. 21, n. 4, p. 663-675, out./dez. 2016.

SCS - Soil Conservation Service. National Engineering Handbook, USDA, 1972.

SEMARH Secretaria de Meio Ambiente e Recursos Hídricos do Distrito Federal. Olhares sobre o lago Paranoá. Brasília, 1999.

SOARES, M. R. G. de J.; FIORI, C. O.; SILVEIRA, C. T. da; KAVISKI, E. Eficiência do método curve number de retenção de águas pluviais. Mercator, Fortaleza, v. 16, e16001, 2017. DOI:

https://doi.org/10.4215/rm2017.e16001 ISSN: 1984-2201.

TEHRANY, M. S.; LEE, M. J.; PRADHAN, B.; JEBUR, M. N.; LEE, S. Flood susceptibility mapping using integrated bivariate and 
multivariate statistical models. Environ. Earth Sci., v. 72, n. 10, p. 4001-4015, 2014.

; PRADHAN, B.; MANSOR, S.;

AHMAD, N. Flood susceptibility assessment using GIS-based support vector machine model with different kernel types. Catena, n. 125, p. 91-101, 2015.

; JEBUR, M. N. Flood

susceptibility analysis and its verification using a novel ensemble support vector machine and frequency ratio method. Stochastic Environmental Research and Risk Assessment [online], v. 28, n. 4, p. 1149-1165, jan. 2015b. Disponível em: DOI: 10.1007/s00477-015-1021-9. Acesso: 01 set. 2020.
; JONES, S.; SHABANI, F. Identifying the essential flood conditioning factors for flood prone area mapping using machine learning techniques. Catena, n. 175, p. 174-192, 2019. TUCCI, C. E. M. Hidrologia: ciência e aplicação. 4 ed. Porto Alegre: ABRH/Editora da UFRGS, 1993.

YALCIN, G.; AKYUREK, Z. Analysing flood vulnerable areas with multicriteria evaluation. In. ISPRS CONGRESS, 20., 2004, , Istanbul. Proceedings... Istanbul-Turkey: ISPRS, 2004. p. 359-364.

ZEE - Zoneamento Ecológico-Econômico do Distrito Federal. Disponível em: http://zee.df.gov.br/dados-espaciais/ Acesso: 14 set. 2020 